\title{
Pemahaman Mahasiswa Pendidikan Biologi Terhadap Pentingnya Penggunaan Tabir Surya
}

\author{
Shafa Tasya Camelia ${ }^{1}$, Risa Dhotus Zahroh ${ }^{1}$, Yessi Meithasari ${ }^{1,}$ Dian Tauhidah $^{1 *}$ \\ ${ }^{1}$ Fakultas Sains dan Teknologi (UIN Walisongo Semarang) \\ *E-mail: diantauhidah@walisongo.ac.id
}

\begin{abstract}
Abstrak: Paparan sinar matahari langsung dalam waktu yang lama dapat menyebabkan berbagai gangguan kesehatan. Sunscreen atau tabir surya dapat mencegah masuknya sinar matahari langsung ke dalam kulit, namun masih banyak masyarakat yang awam tentang pentingnya penggunaan tabir surya. Penelitian ini dilakukan untuk mengetahui pemahaman mahasiswa terhadap pentingnya penggunaan tabir surya. Penelitian ini berupa survei yang dilakukan di prodi Pendidikan Biologi UIN Walisongo Semarang dari berbagai angkatan. Instrumen penelitian berupa angket. Hasil penelitian menunjukan bahwa mahasiswa telah paham akan pentingnya penggunaan tabir surya, namun mereka lebih memilih menggunakan pakaian tertutup dari pada menggunakan tabir surya.
\end{abstract}

\section{Kata Kunci: Tabir Surya, Mahasiswa, Survei}

Abstract: Prolonged exposure to direct sunlight can cause various health problems. Sunscreen can prevent the entry of direct sunlight into the skin, but there are still many people who are unfamiliar about the importance of using sunscreen. This research was conducted to determine student understanding of the importance of using sunscreen. This research was a survey research conducted at Biology Education UIN Walisongo Semarang from various forces. The research instrument was a questionnaire. The results showed that students already understood the importance of sunscreen, but they preferred to wear closed clothing rather than using sunscreen.

\section{Keywords: Sun Screen, Undergraduate Students, Survey}

Matahari merupakan sumber cahaya yang dapat menerangi bumi dan juga sebagai sumber energi. Sinar matahari terbagi menjadi sinar UV A, UV B, dan UV C. Sinar matahari memiliki manfaat alami, yaitu mensintes vitamin D yang dapat mencegah pertumbuhan kanker dan dapat membunuh bakteri (Setiati, 2008), akan tetapi disamping manfaat tersebut, sinar matahari dapat menimbulkan berkas kemerahan, kulit seperti terbakar, dapat memicu pertumbuhan kanker kulit (Pratiwi \& Husni, 2017), kerutan pada kulit, merusak sel kulit (Isfardiyana \& Safitri, 2014) hingga menyebabkan mata katarak 
(Cahyono, 2005). Untuk itu diperlukan perlindungan untuk dapat menjaga kulit tetap sehat dan terhindar dari berbagai macam kerugian yang disebabkan oleh sinar matahari dengan menggunakan tabir surya.

Sunscreen atau tabir surya merupakan bagian dari serangkaian kosmetik yang dapat mencegah masuknya sinar matahari kedalam kulit. Penggunaan tabir surya dianjurkan di negara yang memiliki paparan sinar matahari cukup lama (Tranggono \& Latifah, 2007). Oleh karena itu, dibutuhkan pemakaian tabir surya secara rutin jika beraktifitas diluar ruangan. Mahasiswa pendidikan biologi UIN Walisongo banyak melakukan kegiatan sehari-hari di luar ruangan berkaitan dengan praktik di lapangan sehingga kemungkinan terpapar sinar matahari lebih banyak, terlebih iklim di Ngaliyan Semarang yang cukup panas, di mana suhu tertinggi di Semarang bisa mencapai $39,5^{\circ} \mathrm{C}$ (Badan Pusat Statistik, 2015). Hal ini dapat menyebabkan mereka lebih rentan terkena dampak buruk dari sinar UV, misalnya kerusakan kelopak mata, penuaan dini pada kulit, kanker kulit, dan penyakit kulit lainnya. Data Chung (2001) menunjukan bahwa kulit Asia dapat mengalami photoaging (keriput dan dispegmentasi) bila terpapar cahaya matahari berlebih. Data RISKEDAS (2007) bahkan menunjukan bahwa kanker kulit menjadi penyakit kanker urutan ketiga di Indonesia.

Penggunaan tabir surya secara rutin dapat mengurangi resiko berbagai penyakit kulit (Green dkk., 2011). Adanya pemahaman tentang pentingnya menggunakan tabir surya atau sunscreen dapat menjaga kulit dari kerugian-kerugian yang ditimbulkan oleh sinar matahari. Mahasiswa pendidikan biologi yang telah menempuh berbagai mata kuliah biologi diharapkan memiliki pemahaman yang cukup tentang penggunaan tabir surya. Penelitian sebelumnya yang serupa menunjukan bahwa mahasiswa kedokteran telah memiliki pemahaman yang cukup tentang pentingnya penggunaan tabir surya (Ridlo, 2019). Namun masih belum ada penelitian dengan responden mahasiswa dengan latar belakang pendidikan pedagogi. Padahal sebagian besar lulusan sarjana pendidikan nantinya akan menjadi tenaga pengajar di sekolah, sehingga pengetahuan mereka akan berpengaruh pada pemahaman peserta didiknya kelak. Sehingga dilakukan penelitian ini untuk mengetahui pemahaman mahasiswa pendidikan biologi UIN Walisongo Semarang tentang pentingnya penggunaan tabir surya.

\section{METODE PENELITIAN}

Penelitian ini merupakan penelitian survei. Penelitian dilaksanakan pada bulan Oktober 2019 di Prodi Pendidikan Biologi, Fakultas Sains dan Teknologi, UIN Walisongo Semarang. Populasi penelitian ini adalah seluruh mahasiswa prodi pendidikan biologi UIN Walisongo Semarang dan sampel diambil secara acak dengan tingkat studi yang bervariasi. Instrumen yang digunakan berupa angket dengan skala likert. Data dianalisis secara statistik deskriptif.

BIOLOGI SEL (VOL 9 NO 2 EDISI JUL-DES 2020 ISSN 2252-858X/E-ISSN 2541-1225) PAGE 133 


\section{HASIL DAN PEMBAHASAN}

Dalam penelitian ini, didapatkan responden yang berasal dari program studi Pendidikan Biologi Universitas Islam Negeri Walisongo Semarang yang terbagi atas mahasiswa semester 1, 3, dan 5. Berdasarkan data yang didapat, 63,2\% mahasiswa mengaku belum pernah mendapatkan materi mengenai sinar ultraviolet selama menjadi mahasiswa, sedangkan 23,7 \% mengaku sudah pernah mendapatkan materi tersebut dan sisanya yaitu $13,2 \%$ menjawab ragu-ragu.

Mayoritas responden menaiki sepeda motor $(42,1 \%)$ dan juga berjalan kaki $(44,7 \%)$ dari tempat tinggal menuju kampus, sisanya menaiki mobil ataupun angkutan umum. Gaya hidup responden berkaitan dengan penggunaan tabir surya dijabarkan pada Tabel 1.

Tabel 1. Gaya Hidup Responden

\begin{tabular}{|l|l|c|}
\hline \multicolumn{1}{|c|}{ No } & \multicolumn{1}{|c|}{ Indikator } & Persentase \\
\hline 1. & Beraktivitas di alam terbuka pada siang hari & $78,9 \%$ \\
\hline 2. & Sering terpapar sinar matahari & $100 \%$ \\
\hline 3. & Penggunaan tabir surya & $44,7 \%$ \\
\hline 4. & Perlu menggunakan tabir surya saat beraktivitas diluar ruangan & $78,9 \%$ \\
\hline 5. & Selalu memakai pakaian tertutup saat berpergian & $89,5 \%$ \\
\hline
\end{tabular}

Berdasarkan tabel di atas, 78,9\% mahasiswa sering beraktivitas di alam terbuka pada siang hari dan $21,1 \%$ tidak. Namun pada pertanyaan selanjutnya, semua mahasiswa mengaku sering terpapar sinar matahari saat berada di luar ruangan. Setiap beraktivitas di luar ruangan saat siang hari, 44,7\% mahasiswa Pendidikan Biologi sudah memakai tabir surya untuk melindungi kulit dari paparan langsung sinar ultraviolet, tetapi 55,3\% belum memakai tabir surya.

Perilaku dalam penelitian ini dilanjutkan dengan menanyakan kepada responden apakah tabir surya perlu digunakan apabila sedang beraktivitas di luar ruangan atau tidak. Dapat dilihat pada Tabel 1 bahwa 78,9\% mahasiswa Pendidikan Biologi UIN Walisongo Semarang menganggap penggunaan tabir surya penting, tetapi $21,1 \%$ menganggap tidak penting. Penelitian ini diperinci dengan menanyakan seputar tabir surya yang mengandung SPF dan PA kepada responden, dan hasil yang didapatkan adalah semua responden mengetahui tentang hal tersebut. Kemudian dari 38 responden, 97,4\% sudah mengetahui fungsi dari tabir surya yaitu untuk melindungi kulit dari paparan sinar matahari, tetapi sisanya masih ada yang beranggapan bahwa fungsi dari tabir surya untuk mencerahkan dan menghaluskan kulit.

Kemudian penelitian ini dilanjutkan dengan menanyakan pemahaman mahasiswa Pendidikan Biologi terkait akibat dari kulit yang sering terpapar sinar matahari, 76,3\% menjawab paparan sinar ultraviolet dapat menyebabkan flek hitam dan penuaan dini 
sedangkan 23,7\% mahasiswa menjawab paparan sinar UV dapat menyebabkan flek hitam dan jerawat. Selain itu juga diajukan pertanyaan yang disebabkan oleh radiasi paparan sinar matahari, rata-rata responden menjawab kanker kulit (89,5\%), tetapi juga masih ada yang menjawab panu $(7,9 \%)$ dan sisanya menjawab Lupus Eritematosus.

Setelah melalui beberapa pertanyaan terkait tabir surya dan sinar ultraviolet, diberikan pertanyaan terakhir berupa keinginan untuk menggunakan tabir surya setelah mengetahui bahaya dari paparan sinar UV, 89,5\% responden menjawab akan menggunakan tabir surya, tetapi masih ada $10,5 \%$ responden menjawab tidak. Meskipun terdapat peningkatan sebesar 44,8\% mahasiswa yang tergerak untuk memakai tabir surya setelah memahami pentingnya penggunaan tabir surya, tetapi masih ada beberapa mahasiswa yang menganggap penggunaan tabir surya kurang penting.

Hal tersebut sesuai dengan penelitian sebelumnya yang menunjukan bahwa walaupun pengetahuan tentang pentingnya tabir surya sudah tinggi namun minat untuk menggunakannya masih belum mengimbangi (Ridlo, 2019). Penelitian Pamudji (2017) pun menunjukan tidak adanya hubungan antara tingkat pendidikan dengan pengetahuan penggunaan tabir surya. Bahkan penelitian Wadoe dkk. (2019) pada responden pria menunjukan hasil yang rendah baik pada pengetahuan maupun minat menggunakan tabir surya.

Beberapa mahasiswa Pendidikan Biologi yang berpendapat bahwa penggunaan tabir surya kurang penting disebabkan karena mereka beranggapan jika sinar UV masih dapat dicegah dengan menggunakan pakaian panjang. Sebagian juga berpendapat bahwa body lotion yang mengandung SPF dan PA cenderung mahal dan harganya kurang terjangkau untuk mahasiswa. Menutup seluruh tubuh dengan pakaian panjang memang merupakan salah satu cara agar dapat menghindari paparan sinar UV secara langsung. Tetapi perlu diketahui bahwa kain akan menyerap sinar UV sampai 60\% ke dalam kulit, sehingga masih diperlukan pemakaian tabir surya di seluruh tubuh untuk menghambat sinar UV masuk ke dalam kulit.

Selain itu, kemungkinan penyebab dari kurangnya tingkat pengetahuan mahasiswa Pendidikan Biologi UIN Walisongo Semarang terhadap pentingnya penggunaan tabir surya disebabkan karena kurangnya edukasi mengenai tabir surya dan bahaya paparan sinar ultraviolet secara langsung. Oleh karena itu, diperlukan edukasi kepada para mahasiswa khususnya mahasiswa Pendidikan Biologi agar dapat meningkatkan tingkat pengetahuan, sikap dan perilaku mengenai penggunaan tabir surya.

Pandangan masyarakat untuk menghindari paparan sinar matahari cukup beragam, dari penggunaan pakaian panjang, topi, hingga payung (Urbach, 2001), karena dianggap sebagai proteksi cahaya (Jansen, Wang, Burnett, Osterwalder, \& Lim, 2013) namun hal tersebut belum bisa menjadi pelindung bagi kulit. Daya perlindungan kain dipengaruhi oleh berbagai hal seperti serat dan warna (Tantari, 2003). Tabir surya merupakan perlindungan yang lebih baik meski masih ada kontroversi penggunaannya 
berkaitan dengan efek samping, kandungan yang dimiliki (Jansen, Osterwalder, Wang, Burnett, \& Lim, 2013), serta reaksi alergi yang mungkin muncul (Wong \& Orton, 2011).

Beberapa penelitian terkini diketahui telah banyak pengembangan tabir surya menggunakan bahan alami seperti jagung (Lumempouw dkk., 2012), daun sendok (Fitri, 2010), hingga tabir surya buatan sendiri (Isfardiyana \& Safitri, 2014). Indonesia sebagai negara tropis memiliki banyak tanaman yang mengandung fitokonstituen sebagai bahan aktif sediaan tabir surya (Pratiwi \& Husni, 2017). Cara lain yang dapat digunakan untuk mengurangi dampak buruk paparan sinar ultraviolet adalah konsumsi vitamin E (Alioes $\&$ Sy, 2015) atau bahan alami lain non-sunscreen yang lebih alami (Matsui dkk., 2009).

Penelitian Kaidbey \& Kigman (1987) sebelumnya menjelaskan jika pigmen kulit dapat mengurangi kemungkinan penyakit kulit karena sengatan sinar matahari. Penelitian Chung (2011) menunjukan bahwa seseorang dengan kulit gelap lebih dapat bertahan lama di bawah sinar matahari kaitannya dengan kulit terbakar (sunburn). Indonesia sebagai negara tropis dengan warna kulit masyarakatnya yang sawo matang seringkali menganggap pigmen kulit mereka sudah cukup melindungi. Penggunaan tabir surya di daerah tropis tetap diperlukan guna menangkal sinar ultraviolet masuk ke dalam kulit (Mukti, 2014).

Pengetahuan mengenai jenis tabir surya pun sangat diperlukan, tidak hanya sekedar paham pentingnya penggunaan tabir surya. Pemilihan jenis tabir surya yang tepat dan waktu yang tepat dapat mengurangi dampak paparan sinar matahari (Minerva, 2019). Penggunaan tabir surya berlebihan juga dapat menimbulkan dampak buruk bagi kulit. Don (2011) dalam bukunya menjelaskan bahwa penggunaan tabir surya dapat mengganggu kerja endokrin (pengeluaran keringat) dan menghalangi produksi vitamin D. Vitamin D hanya dapat diproduksi tubuh ketika terkena paparan sinar matahari. Sehingga waktu penggunaan sun screen juga perlu diperhatikan, agar tetap dapat kita rasakan manfaatnya tanpa memberikan dampak buruk bagi tubuh.

\section{KESIMPULAN}

Hasil penelitian ini memperlihatkan bahwa pemahaman mahasiswa Pendidikan Biologi UIN Walisongo Semarang terhadap tabir surya sudah cukup bagus. Mereka mengetahui arti, dampak, serta cara mengatasi terhadap paparan sinar UV. Adanya perbedaan pemahaman antara yang sudah menggunakan tabir surya dan tidak menggunakan disebabkan karena adanya perbedaan persepsi tentang pentingnya tabir surya sebagai pelindung kulit dari bahaya radiasi matahari. Oleh karena itu, diperlukan edukasi kepada para mahasiswa khususnya mahasiswa Pendidikan Biologi terutama yang sering melakukan praktik lapangan dan terpapar matahari langsung agar dapat meningkatkan tingkat pengetahuan, sikap dan perilaku mengenai penggunaan tabir surya. 


\section{DAFTAR PUSTAKA}

Alioes, Y., \& Sy, E. (2015). Efek Pemberian Vitamin E Terhadap Jumlah Erytrosit Dan Aktivitas Enzim Katalase Tikus Akibat Paparan Sinar Ultraviolet. Jurnal Riset Kimia, 4(1), 97. https://doi.org/10.25077/jrk.v4i1.113

Badan Penelitian dan Pengembangan Kementerian Kesehatan RI. (2007). RISKESDAS 2007. Jakarta: Kementerian Kesehatan RI.

Badan Pusat Statistik. (2015). Suhu Minimum, Rata-rata, dan Maksimum di Stasiun Pengamatan BMKG $\left({ }^{0} \mathrm{C}\right), 2011-2015$. www.bps.go.id

Cahyono, W. E. (2005). Dampak Peningkatan Radiasi Ultraviolet B. Peneliti Bidang Pengkajian Ozon Dan Polusi Udara, LAPAN, 22-26.

Chung, J. H. (2001). The Effects of Sunlight on the Skin of Asians (Chapter 4 Sun Protection in Man). New York: Elsevier.

Don. (2011). SPF Zero Chemical Sunscreen Exposed. Illinois: eBookIt.com.

Fitri, S. A. (2010). Efektivitas Sedian Krim Fraksi Etanol Dari Infus Daun Sendok (Plantago mayor L.) Sebagai Tabir Surya. Skripsi. Makassar: UIN Alauddin Makassar.

Green, A.C., Williams, G.M., Logan, V. and Strutton, G.M., (2011). Reduced melanoma after regular sunscreen use: randomized trial follow-up. Journal of clinical oncology, 29(3), pp.257-263.

Isfardiyana, S. H., \& Safitri, S. R. (2014). Pentingnya Melindungi Kulit Dari Sinar Ultraviolet dan Cara Melindungi Kulit dengan Sunblock Buatan Sendiri. Jurnal Inovasi dan Kewirausahaan. 3(2): 126-133.

Jansen, R., Osterwalder, U., Wang, S. Q., Burnett, M., \& Lim, H. W. (2013). Photoprotection: Part II. Sunscreen: Development, efficacy, and controversies. Journal of the American Academy of Dermatology, 69(6), 867.e1-867.e14. https://doi.org/10.1016/j.jaad.2013.08.022

Jansen, R., Wang, S. Q., Burnett, M., Osterwalder, U., \& Lim, H. W. (2013). Photoprotection: Part I. Photoprotection by naturally occurring, physical, and systemic agents. Journal of the American Academy of Dermatology, 69(6), 853.e1-853.e12. https://doi.org/10.1016/j.jaad.2013.08.021

Kaidbey, K.H. and Kligman, A.M. (1978). Sunburn protection by longwave ultraviolet radiation-induced pigmentation. Archives of dermatology, 114(1), pp.46-48.

Lumempouw, L., Suryanto, E. and Paendong, J., (2012). Aktivitas anti UV-B ekstrak fenolik dari tongkol jagung (Zea mays L.). Jurnal MIPA, 1(1), pp.1-4.

Matsui, M.S., Hsia, A., Miller, J.D., Hanneman, K., Scull, H., Cooper, K.D. and Baron, E., (2009). August. Non-sunscreen photoprotection: antioxidants add value to a sunscreen. In Journal of Investigative Dermatology Symposium Proceedings (Vol. 14, No. 1, pp. 56-59). Elsevier. 
Minerva, P. (2019). Penggunaan Tabir Surya bagi Kesehatan Kulit. Jurnal Pendidikan dan Keluarga, 11 (1): 95-101.

Mukti, R. A. (2014). Tabir Surya VS Iklim Tropis. Jurnal. (18): 61-66.

Pamudji, R. 2017. Hubungan Tingkat Pendidikan dengan Pengetahuan Mengenai Penggunaan Tabir Surya. Syifa' MEDIKA: Jurnal Kedokteran dan Kesehatan, 8 (1).

Pratiwi, S., \& Husni, P. (2017). Artikel Tinjauan: Potensi Penggunaan Fitokonstituen Tanaman Indonesia Sebagai Bahan Aktif Tabir Surya. J. Farmaka, 15(4), 18-25.

Setiati, S., (2008). Pengaruh Pajanan Sinar Ultraviolet B Bersumber dari Sinar Matahari terhadap Konsentrasi Vitamin D $(25(\mathrm{OH})$ D) dan Hormon Paratiroit pada Perempuan Usia Lanjut Indonesia. Kesmas: National Public Health Journal, 2(4), pp.147-153.

Ranggono, R. I. dan Latifah, F. (2007). Buku Pegangan Ilmu Pengetahuan Kosmetik. Jakarta: Gramedia.

Ridlo, M. R. (2019). Pandangan Mahasiswa Tingkat Satu Kedokteran UNS terhadap Pentingnya Penggunaan Tabir Surya. INA-Rxiv https://doi.org/10.31227/osf.io/rkhmj

Tantari, S. H. W. 2003. Pakaian sebagai Pelindung Surya. Majalah Kedokteran Universitas Brawijaya, XIX (2).

Urbach, F., (2001). The historical aspects of sunscreens. Journal of photochemistry and photobiology B: Biology, 64(2-3), pp.99-104.

Wadoe, M., Syifaudin, D. S., Alfianna, W., Aifa, F. F., Narlika, D. P., Savitri, R. A., Andri, M. D., Ikhsan, N. D. M., Manggala, A., Fauzi, I. Q. K., Ayu, N., Mutrikah, dan Sulistyarini, A. (2019). Penggunaan dan Pengetahuan Suncreen pada Mahasiswa UNAIR. Jurnal Farmasi Komunitas, 6 (1): 1-8.

Wong, T. and Orton, D., (2011). Sunscreen allergy and its investigation. Clinics in dermatology, 29(3), pp. 306-310. 